\title{
APRESENTAÇÃO DO DOSSIÊ Música Popular e Interdisciplinaridade
}

Dentre as diversas expressões artísticas, a chamada música popular - termo que embora discutível se consagrou para distinguir a "música industrializada/de entretenimento" da "erudita/culta" e da "folclórica" - é, sem dúvida, aquela que consegue perpassar diferentes classes sociais, em muito devido ao registro fonográfico. A possibilidade de gravação, reprodução e veiculação, esta última principalmente com o advento do rádio, contribuiu consideravelmente com esse processo, trazendo também como consequência a adequação da música popular a um conjunto de condicionantes estéticos e formais. Se por um lado isso possibilita a sua difusão, por outro pode acarretar na padronização do ouvido. De todo modo, a música popular - por si só polissêmica - é intrínseca ao processo social, exprimindo, não só em suas letras, mas em tudo aquilo que a compõe, aspectos-chave para a compreensão sócio-histórica. Apreender as suas diversas camadas de sentido, buscando perscrutar nexos e contradições sociais, tem revelado novas problemáticas para os pesquisadores.

Nas palavras da antropóloga Elizabeth Travassos, a música popular, que desde a primeira metade do século $\mathrm{XX}$ se constituiu como um dos temas privilegiados do noticiário jornalístico, teve a sua relevância social, política e econômica não raras vezes desconsiderada ou até mesmo inferiorizada no meio acadêmico. O fato é que - dizia ela - "há não muito tempo os estudiosos da música popular precisavam convencer os colegas da dignidade de seu objeto, na dupla frente das ciências sociais e dos saberes musicológicos" ${ }^{1}$. Salvo engano, já não precisamos, hoje, convencer

${ }^{1}$ Cf. TRAVASSOS, Elizabeth. "Pontos de escuta da música popular no Brasil". In: ULHÔA, Martha; OCHOA, Ana Maria (orgs.). Música popular na América Latina. Porto Alegre: Ed. UFRGS, 2005, p. 94-111, esp. 95. 
os nossos colegas neste sentido. A música popular no Brasil - que atualmente conta com várias referências de fôlego - vem conquistando um espaço significativo na academia ${ }^{2}$. Por constatar, entretanto, que esse objeto plural de estudos ainda consiste num campo de conhecimento em construção, especialmente no que diz respeito às Ciências Sociais - nossa área de atuação em comum -, foi que pensamos e organizamos o dossiê Música Popular e Interdisciplinaridade.

Objetivamos, portanto, realçar análises empenhadas em articular produções e manifestações musicais (canções, discos e grupos), bem como elementos específicos à linguagem da música popular (como gravações e interpretações), com questões de cunho sócio-histórico, abordadas nos cinco artigos e nas duas resenhas contempladas no dossiê.

Abrindo a seção temática, José Adriano Fenerick, em "Arrigo Barnabé e o pop-rock nos anos $80^{\prime \prime}$, discute a presença do rock e do pop na produção musical do ícone da chamada Vanguarda Paulista, tecendo, inicialmente, uma reflexão sobre a "dialética oculta" que haveria entre vanguarda e música popular. Arrigo, conhecido por suas ousadias quanto à utilização de procedimentos dodecafônicos e atonais na música, raramente é vinculado ao rock e ao pop dos anos 1980, uma relação que, permeada de criticidade e tensões, Fenerick elucida ao analisar algumas canções do emblemático disco Tubarões Voadores (1984).

\footnotetext{
${ }^{2}$ Ver, por exemplo: DIAS, Márcia Tosta. Os donos da voz: indústria fonográfica brasileira e mundialização da cultura. São Paulo: Boitempo/Fapesp, 2000; NAPOLITANO, Marcos. "Seguindo a canção": engajamento político e indústria cultural na MPB (1959-1969). São Paulo: Annablume/Fapesp, 2001; NAVES, Santuza Cambraia. Canção popular no Brasil: a canção crítica. Rio de Janeiro: Civilização Brasileira, 2010; SANDRONI, Carlos. Feitiço decente: transformações do samba no Rio de Janeiro (1917-1933). Rio de Janeiro: Ed. UFRJ/Zahar, 2001; TATIT, Luiz. O século da canção. Cotia: Ateliê, 2004; VIANNA, Hermano. O mundo funk carioca. Rio de Janeiro: Jorge Zahar, 1988; ZAN, José Roberto. Do fundo do quintal à vanguarda: contribuição para uma história social da música popular brasileira. Tese de doutorado em Sociologia. Campinas: Unicamp/IFCH, 1996.
} 
A cidade de São Paulo, berço de Arrigo e de seus companheiros da Vanguarda Paulista, foi também cantada por Adoniran Barbosa a partir da década de 1950 - período marcado por intensas transformações socioeconômicas no Brasil. As letras de alguns de seus sambas foram devidamente cotejadas com o debate sobre o desenvolvimentismo no país no artigo "As faces sedutora e violenta do 'progresso' em Adoniran Barbosa". Thiago Franco, Lucas Andrietta, Thiago Aoki, Robson Gabioneta e Fernando Pedrazolli Filho, pesquisadores que se dedicam a explorar as fronteiras e as conexões entre o universo do samba e o das Ciências Humanas, nos mostram como o ideário do progresso foi a um só tempo retratado e denunciado em canções do célebre compositor.

Se o contexto ditatorial aparece até então como pano de fundo, ele agora dá o tom no artigo de Carlos Eduardo Amaral de Paiva. Em "Wilson Simonal: vida e morte de um superastro negro", o autor avalia a polêmica relação do artista com o regime militar. No entanto, argumenta como tal relação camuflava o que de fato melhor explicaria o ostracismo pelo qual passou o "superastro negro": as relações sociais estruturadas no mito da democracia racial.

$\mathrm{Na}$ esteira da problemática étnico-racial, combinada com a discussão de gênero, temos o artigo "Leci e Januário: escrivivências negras contemporâneas na música e fotografia". Elisângela de Jesus Santos e Vilma Neres Bispo demonstram, baseando-se na noção de escrivivências de Conceição Evaristo, que canção e imagem, entrelaçadas, desvendam subjetividades e lugares de memória não separados das trajetórias e das relações sociais de Leci Brandão e de Januário Garcia, fotógrafo responsável por várias capas de discos da sambista, compositora e intérprete, como, por exemplo, os LPs Coisas do meu pessoal (1977) e Essa tal criatura (1980), destacados pelas autoras.

Os anos 1970 também contextualizam as análises de Nívea Lins Santos em "A mímesis do Quinteto Armorial: uma busca pela autenticidade da música brasileira", no qual mobiliza o conceito de mímesis para sublinhar como o grupo idealizado 
por Ariano Suassuna se orientava em prol da construção desta "autenticidade". Reelaborando em sua produção musical uma gama de referências consideradas tradicionais e nordestinas, o Quinteto Armorial teria se posicionado criticamente à "modernidade" que se consolidava no Brasil naquela década.

Esse número da Idéias conta igualmente com seis artigos em sua seção livre. Os dois primeiros, assinados respectivamente por Maria Janaína Brenga Marques e por Aline Brasiliense dos Santos Brito, desenvolvem reflexões na área de estudos da Filosofia. Em "O livre arbítrio em Agostinho: gênese do conceito no livro VII das Confissões", Maria Marques, ao tratar das transformações da concepção de livre-arbítrio em Agostinho, salienta como esse processo esteve ligado à sua conversão ao Cristianismo. Aline Brito, em Conceito de representação inconsciente em Kant e Wolff, explora um assunto ainda recente, lançando mão de critérios de "clareza-obscuridade" para compreender as referências críticas desses dois pensadores acerca do conceito que enunciam.

Já em Interfaces entre gênero e dependência química, Janine Targino debruça-se sobreas experiências demulheres quimicamente dependentes, enfatizando, ao entrecruzar referências bibliográficas com as entrevistas que realizou, o gênero como norteador de sua observação. Na sequência, Rosa Colman, Marta Azevedo e Bárbara Estanislau discutem, em "Os Guarani e o seu modo de ser caminhante", teorias que procuram apreender o fenômeno da migração dos povos indígenas, sobretudo os Guarani e Kaiowá, articulando, para tanto, conceitos demográficos e de migração. E, finalizando esta seção livre, Vinicius Alves do Amaral problematiza o uso de princípios e métodos biográficos específicos ao ofício do historiador, jogando luz sobre o diálogo entre a historiografia e a literatura em seu artigo "Beco sem saída ou ponto de partida?: a ilusão biográfica e os historiadores".

A tradução que incorporamos a este número da Idéias foi realizada por Danilo Arnaut e João Gomes da Silva Filho: "Engajamento sociológico e a abordagem típico-idealista", texto, 
homônimo ao original em francês, do sociólogo Alain Caillé, professor da Universidade Paris X-Nanterre e fundador da Revue du MAUSS (Mouvement anti-utilitariste dans les Sciences Sociales). A tradução corresponde à versão definitiva do texto, publicado em 2015 no livro La Sociologie malgré tout: fragments d'une sociologie générale (Presses Universitaires de Paris-Ouest). A partir de suas próprias experiências, Caillé nos oferece uma importante reflexão sobre o engajamento sociológico na atualidade.

Duas resenhas dedicadas à música popular, ambas de livros publicados em 2016, encerram este volume da revista. Na primeira, "Um mapeamento das possibilidades da pesquisa em música sob a perspectiva das Ciências Sociais", Carla Delgado de Souza traça um panorama de Música e Ciências Sociais: para além do descompasso entre arte e ciência (Curitiba, ed. Prismas), livro organizado por Carlos Sandroni e Dmitri Cerboncini Fernandes. Souza chama a atenção, sobretudo, para as inovações metodológicas que embasam os capítulos da coletânea, mesmo quando os seus autores revisitam temas já consagrados pela literatura. Na segunda, "Novos paradigmas da produção musical independente no pós-internet", Renato Gonçalves expõe com detalhes Cena musical paulistana dos anos 2010: a "música brasileira" depois da internet (São Paulo, ed. Annablume/Fapesp), livro de Thiago Galleta. Ao se concentrar na atual "cena musical paulistana independente", Galleta evidencia o quanto o advento da internet modificou radicalmente a produção, a veiculação e o consumo de música. Embora o livro, conforme salienta Gonçalves, deixe em aberto algumas questões referentes ao assunto proposto, visto que se trata de um fenômeno em processo, ele nos instiga a estar atentos aos desafios que se colocam para o estudo da música popular feita no Brasil na era da internet.

Certos de que o material que organizamos possa contribuir com novas agendas de pesquisa sobre a música popular, nós agradecemos a todos os membros do corpo editorial da revista que nos auxiliaram na elaboração deste dossiê, e, também, a Barbara Luisa Pires pela arte da capa, a Maria Cimélia Garcia e ao Setor de Publicações do Instituto de Filosofia e Ciências 
Humanas da Unicamp. E, claro, somos especialmente gratos às autoras e aos autores dos artigos, tradução e resenhas que tornaram possível a concretização de mais este número da Idéias. Boa leitura!

\section{Daniela Vieira dos Santos ${ }^{3}$ Rodrigo Pezzonia ${ }^{4}$ Sheyla Castro Diniz}

Editores da Revista Idéias, v. 8, n. 2, jul./ dez. 2017

${ }^{3}$ Doutora em Sociologia pela Unicamp. Atualmente é pós-doutoranda junto ao Departamento de Sociologia da Unicamp, com bolsa da FAPESP. Autora do livro "Não vá se perder por aî": a trajetória dos Mutantes. São Paulo: Annablume/ Fapesp, 2010. Contato: santos.danielavieira@gmail.com.

${ }^{4}$ Doutor em História Social (USP), mestre em Sociologia (UNICAMP) e licenciado em História (UNESP-Assis), atualmente desenvolve pesquisa de pós-doutorado junto ao Departamento de Sociologia do Instituto de Filosofia e Ciências Humanas da Universidade Estadual de Campinas. Contato: pezzonia@gmail.com.

${ }^{5}$ Doutora e mestre em Sociologia da Cultura pela Unicamp; graduada em Música e em Ciências Sociais pela Universidade Federal de Uberlândia. Autora do livro "... De tudo que a gente sonhou": amigos e canções do Clube da Esquina. São Paulo: Intermeios/Fapesp, 2017. Contato: sheyladiniz@yahoo.com.br. 